\title{
Diet profiles in a population sample from Mediterranean southern France
}

\author{
Jacqueline Scali, Aurélia Richard and Mariette Gerber* \\ Groupe d'Epidémiologie Métabolique, INSERM-CRLC, 34298 Montpellier Cedex 5, France
}

Submitted 17 January 2000: Accepted 7 July 2000

\begin{abstract}
Objective: A Mediterranean diet quality index (MDQI) was devised to give an overall assessment of dietary habits and to identify groups at risk.

Design: The MDQI was based on scores given for selected levels of consumption of selected nutrients and foods.

Setting: Mediterranean southern France.

Subjects: The sample included 473 men and 491 women in three age classes recruited at random.

Results: Only $9.5 \%$ of men, $9.0 \%$ of women, $4.7 \%$ of $20-34$ year old subjects, $6.6 \%$ of 35-54 year old subjects and $14.0 \%$ of 55-76 year old subjects were shown to have a healthy diet. However, $10.1 \%$ of men, $8.6 \%$ of women, $19.4 \%$ of $20-34$ year old subjects, $10.2 \%$ of $35-54$ year old subjects and $4.6 \%$ of $55-76$ year old subjects were shown to have a poor diet. There were significantly fewer smokers among subjects with a good diet but the distribution of moderate wine drinkers was comparable between those with a good diet and those with a poor diet. Correspondence analysis associated a healthy diet with 55-76 year old men and women living in rural areas, who had received primary schooling only and who were manual workers. Both men and women with a poor MDQI score tended to be young and smokers. In addition, women with a poor MDQI tended to be heavy drinkers and obese.

Conclusions: This study showed that the Mediterranean model, which is generally recognized as a healthy diet, appears restricted to older people and to rural areas, whereas urbanized young people depart from it. A nutritional prevention policy targeted at young adults is required to encourage them to adhere to the Mediterranean model. Smoking and drinking showed different distribution patterns in the sample under study.
\end{abstract}

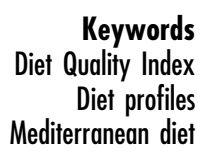

A growing body of evidence, including the failure of single-nutrient supplementation in protecting against cardiovascular disease ${ }^{1-4}$, cancers 5,6 or pre-cancerous states $^{7,8}$ and the apparent advantage of a combination of nutrients ${ }^{9,10}$, supports a holistic view of the relationship between food intake and disease. It is now no longer thought that a single nutrient can protect against disease. Current thinking is that diet must be considered globally, in terms not only of food categories but also of food variety and preparation, and of the pattern of meals during the day and over the seasons. The holistic approach provides useful information for assessing the relationship between food and the health of the general population. Several authors have devised instruments for measuring an overall diet quality that reflects a risk gradient for major diet-related chronic diseases. Such instruments are based on current dietary guidelines ${ }^{11-14}$ or on the Diet and Health Recommendations of the USA
National Research Council ${ }^{15}$. Because of differences in food habits, however, these instruments have to be adapted to the local population. We devised a diet quality index suited to a Mediterranean population and applied it to the population of the Hérault department of southern France. This Mediterranean Diet Quality Index (MDQI) has been validated by biological markers in a subsample of the same population ${ }^{16}$. The distribution of scores for good and poor diet among various classes of population and the characteristics of the population groups in the good diet and poor diet categories were then analysed. It is therefore possible to propose nutritional guidelines for specific population groups.

\section{Methods}

\section{Subjects}

The population under study was a randomly recruited 
sample of 989 subjects in three age classes: 20-34, 35-54 and 55-76 years. The study was conducted in the Hérault department (southern France) between January 1994 and November $1996^{17}$. Randomization was achieved by drawing the potential subjects from electoral lists. Of those invited, $73 \%$ either did not answer or refused to participate. Of the responders, $48 \%$ agreed to participate in the study.

Four socio-economic areas of the Hérault have been defined by Padilla ${ }^{18}$, making it possible to study the effects of socio-economic variables on dietary habits: Greater Montpellier, the regional capital and its surroundings; the Bassin de Thau, a coastal area characterized by a sea port, fisheries and a seafood economy; the Bitterrois, an area where wine-growing is the main occupation; and the Hauts-Cantons, a depopulated rural area with a high percentage of older people. These areas were defined according to such variables as income, demographic characteristics, unemployment, women's activities and the number of supermarkets and fast-food outlets. Our total sample was demographically representative of these subregions.

Three subjects were eliminated because no information was available for body mass index (BMI) assessment, and under-reporters were also excluded. The cut-off for exclusion was a calory intake of $<1900 \mathrm{kcal}$ for men and $<1500 \mathrm{kcal}$ for women, except for four men and nine women, who declared an energy expenditure related to physical activity of no more than $10 \%$ of their intake. Energy expenditure related to physical activity was calculated according to Ainsworth et $a l^{19}$. The final sample consisted of 964 subjects, 473 men and 491 women.

\section{Nutritional data}

Nutritional data were collected using a validated food frequency questionnaire $(\mathrm{FFQ})^{20}$, an extended version of one used in previous studies ${ }^{21-23}$. The interview was conducted by a trained assistant and lasted 45-60 minutes. The FFQ questionnaire asked the subject to recall 'average use over the past year'. It consisted of 162 items arranged by food type and meal pattern, and portions were estimated using a validated set of photographs $^{20}$. Frequency categories were based on the number of times that items were consumed per day, per week or per month. Consumption less than once a month was considered as nil consumption. The relevant period of consumption of seasonal items (e.g. cantaloupe melons, grapes, figs, strawberries), was taken into consideration by dividing the item weight by the fraction of the year corresponding to the length of the season in months, as defined by national data ${ }^{24}$

Edible fractions of foods were recorded in the database. Food values were converted to nutrient values using the 'Fruit d'Or' program, kindly donated by ASTRA-CALVÉ. The database for the program was UNIDAP, which to a large extent uses the values of McCance and Widdowson's food composition tables ${ }^{25}$. We complemented this database with data for specific French foods taken from the Régal database ${ }^{26}$ and with regional recipes. Our current database consists of about 900 items and has values for 36 different nutrients.

\section{Diet Quality Index (DQI)}

A diet quality index is an estimation of the diet as a whole, based on the quantitative consumption of several foods according with recommendations for the prevention of diet-related diseases. Each nutrient or food group is assigned a score on the basis of nutritional guidelines. Scores for all subjects are totalled to obtain the DQI.

A DQI has been designed by Patterson et al. ${ }^{13}$ to describe adult food consumption in relation to the prevention of chronic diseases. The index was based on the principles of the Diet and Health Recommendations ${ }^{15}$ and on those of the American Heart Association ${ }^{27}$. A higher index indicated a poorer quality of diet.

The DQI based on these recommendations did not fit our population because the 'total fat' and 'protein intake' variables did not show a gradient of consumption with increasing scores. We therefore decided to convert the DQI into a Mediterranean DQI (MDQI). The index was adapted to a population living in a Mediterranean area. Olive oil was added with a score increasing with a lower intake, because of its known beneficial effect for cardiovascular diseases ${ }^{28,29}$ and its suggested beneficial effect for some cancers ${ }^{28,30}$. Protein was replaced by meat, because fish was added with an opposite score gradient. In the meat group we included processed and fresh-cut beef, veal, mutton, lamb and pork. Fish included white and fatty fish. This decision was the result of epidemiological findings showing that meat and fish intake had opposite relationships for cardiovascular diseases $^{31-33}$ and some cancers ${ }^{34-39}$. Complex carbohydrates were deleted and replaced by cereals. The cereals group consisted of all types of bread (wheat, barley, plain and whole-grain), pasta (plain and whole-grain) and rice (plain and whole-grain), together with breakfast cereals. We excluded fast food and pastries. Saturated fat, cholesterol and fruit and vegetables were left unchanged, resulting in a total of seven variables. The fruit and vegetables group consisted of all types of red, yellow and green vegetables, both cooked and raw, and all types of fresh fruit. The scores are described in Table 1. When there was no specific recommendation, the food intake limits were obtained by dividing the population's consumption into tertiles. Scores were totalled for each subject, giving a total score for the MDQI. The lower the MDQI, the healthier the diet.

\section{Statistical analysis}

All analyses were performed with SAS (version 6.11; SAS Institute Inc., Cary, NC). Subjects were stratified into four 
Table 1 Construction of the score

\begin{tabular}{cccccccc}
\hline Score & SFA (\% energy) & Cholesterol $(\mathrm{mg})$ & Meats $(\mathrm{g})$ & Olive oil $(\mathrm{ml})$ & Fish $(\mathrm{g})$ & Cereals $(\mathrm{g})$ & Vegetables + fruits $(\mathrm{g})$ \\
\hline 0 & $<10$ & $<300$ & $<25$ & $>15$ & $>60$ & $>300$ & $>700$ \\
1 & $10-13$ & $300-400$ & $25-125$ & $15-5$ & $60-30$ & $300-100$ & $700-400$ \\
2 & $>13$ & $>400$ & $>125$ & $<5$ & $<30$ & $<100$ & $<400$ \\
\hline
\end{tabular}

classes of residency, of socio-economic areas and occupation, three classes of education level (primary school, high school and university), of BMI by grouping the extreme classes defined by the Obesity Task Force ${ }^{40}$, smokers and non-smokers and supplement use or not. For alcohol intake, alcohol and wine intake were highly correlated, thus we decided to show only the distribution of wine consumption $\quad\left(<100 \mathrm{ml} \mathrm{day}^{-1}, \quad 100-\right.$

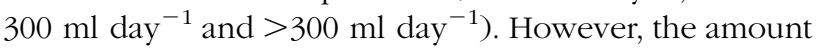
of wine consumed relative to the total alcohol consumption was analysed by comparing the distribution of tertiles of the wine alcohol/total alcohol ratio. $\chi^{2}$ tests were used to compare the distribution of these categories between sexes and age classes of the total sample, and between subjects with a good and a poor diet. To describe the profile of the subjects belonging to each MDQI class, we used correspondence analysis with the correspondence analysis procedure in SAS. The subjects in each MDQI class, identified by their scores, were analysed by sex, in a disjunctive table across age, socio-economic variables (residence in sub-regions, and rural or urban area, socioprofessional class, education) and food-related variables (BMI, tobacco use, wine consumption, wine alcohol/total alcohol ratio).

\section{Results}

The characteristics of the final sample are shown in Table 2. The distribution of subjects by residence categories and socio-economic areas is homogeneous among sex and age classes, except for a higher percentage of the 20-34 age class in Greater Montpellier compared with each of the other age classes, and a lower one in Bassin de Thau compared with the oldest age class. Most of the subjects in category 0 for occupation were found in the young age class because 'students' pertain to this category. For the same reason, the lowest proportion of low level of education was found in the young age class. The heterogeneous distribution of occupation and education among the different age classes designates these variables as potential confounders of age.

The distributions of all other variables (BMI, tobacco use, wine intake, wine/total alcohol ratio and supplement intake) were significantly different between men and women: a higher percentage of men were overweight, smokers and drinkers, but a higher percentage of women took supplements and had a lower wine contribution to their total alcohol intake. Significant differences were found between the young and oldest age classes in the distribution of the same variables except for supplement intake. Most of the young age class showed an ideal BMI and, compared with the oldest age class, more of them drank less wine and alcohol but had a lower wine contribution to their alcohol intake.

The median values for each item included in the scores are shown in Table 3 for each MDQI value computed for the total sample. No subjects scored 0. Scores of $1-4$ (9.2\% of subjects) were grouped together under 'Good MDQI', scores of 5-7 (36.5\%) under 'Medium-to-Good MDQI', scores of 8-10 (44.4\%) under 'Medium-to-Poor MDQI' and scores of 11-13 (9.9\%) under 'Poor MDQI'. The same was done for men and women and for the age classes 20-34, 35-54 and 55-76 years (results not shown). Forty-five men (9.5\%) and 44 women (9\%) had a healthy diet. Only 10 young subjects (4.7\%) had a healthy diet and eight of them had a score of 4. Forty-one young subjects (19.4\%) had a poor MDQI, twenty-four 35-54 year olds (6.6\%) had a good MDQI and $37(10.2 \%)$ had a poor MDQI. Fifty-five 55-76 year olds (14.0\%) had a good MDQI and only 18 (4.6\%) a poor one.

None of the subjects in the Good MDQI category ate enough of the recommended cereals. Only $0.7 \%$ approached the limit for a 0 score, with an intake of $296 \mathrm{~g}$. This was the case with both sexes (medians of $214 \mathrm{~g}$ in men and $180 \mathrm{~g}$ in women) and also with 35-54 year olds (median $214 \mathrm{~g}$ ) and 55-76 year olds (median $186 \mathrm{~g}$ ). Most subjects with a good MDQI ate too much meat (median for both sexes and all ages 39-41 g). However, $9.9 \%$ of those in the Poor MDQI category (scores 11 and 12) had a cereal intake above the score limit, especially men (median $189 \mathrm{~g}$ ), and $6.8 \%$ of them had a meat intake below the score limit in all age classes (20-34 year olds, median 123 g; 35-54 year olds, median $99 \mathrm{~g} ;$ 55-76 year olds, median $110 \mathrm{~g}$ ). The proportion of energy intake provided by saturated fat was slightly over $10 \%$ in 32 women (median 10.7\%).

The distribution of socio-economic and individual factors possibly associated with diet among the subjects with a good or poor MDQI, as a group or stratified according to sex and age, is shown in Table 4.

A significant difference in the distribution of classes of residence was observed between men with a good diet and men with a poor diet, the men with a good diet being more likely to live in a rural area. Similarly, a significant difference in the distribution of the different socioeconomic areas was found between all the subjects with a good diet and those with a bad diet, who were more likely to live in the Greater Montpellier area. Also the 
Table 2 Characteristics of the sample

\begin{tabular}{|c|c|c|c|c|c|c|c|c|c|c|c|c|}
\hline & \multicolumn{2}{|c|}{ Total sample } & \multicolumn{2}{|c|}{ Men } & \multicolumn{2}{|c|}{ Women } & \multicolumn{2}{|c|}{ 20-34 year olds } & \multicolumn{2}{|c|}{$35-54$ year olds } & \multicolumn{2}{|c|}{$55-76$ year olds } \\
\hline & $N$ & $\%$ & $N$ & $\%$ & $N$ & $\%$ & $N$ & $\%$ & $N$ & $\%$ & $N$ & $\%$ \\
\hline \multicolumn{13}{|l|}{ Residency* } \\
\hline$<2000$ & 148 & 15.4 & 78 & 16.5 & 70 & 14.3 & 31 & 14.7 & 49 & 13.6 & 68 & 17.3 \\
\hline $2000-10,000$ & 236 & 24.5 & 120 & 25.4 & 116 & 23.6 & 53 & 25.1 & 92 & 25.6 & 91 & 23.2 \\
\hline$>10,000-100,000$ & 258 & 26.8 & 118 & 24.9 & 140 & 28.5 & 46 & 21.8 & 94 & 26.1 & 118 & 30.0 \\
\hline$>100,000$ & 322 & 33.4 & 157 & 33.2 & 165 & 33.6 & 81 & 38.4 & 125 & 34.7 & 116 & 29.5 \\
\hline \multicolumn{13}{|l|}{ Socio-economic area† } \\
\hline Greater Montpellier & 476 & 49.4 & 235 & 49.7 & 241 & 49.1 & 127 & $60.2^{\mathrm{ab}}$ & 178 & $49.4^{\mathrm{b}}$ & 171 & $43.5^{\mathrm{a}}$ \\
\hline Bassin de Thau & 174 & 18.1 & 76 & 16.1 & 98 & 19.9 & 27 & $12.8^{\mathrm{C}}$ & 61 & 16.9 & 86 & $21.9^{c}$ \\
\hline Biterrois & 227 & 23.5 & 122 & 25.8 & 105 & 21.4 & 36 & 17.1 & 94 & 26.1 & 97 & 24.7 \\
\hline Hauts-Cantons & 87 & 9.0 & 40 & 8.4 & 47 & 9.6 & 21 & 9.9 & 27 & 7.5 & 39 & 9.9 \\
\hline \multicolumn{13}{|l|}{ Occupationł } \\
\hline 0 & 51 & 5.3 & 20 & 4.3 & 31 & 6.3 & 49 & 23.2 & 0 & & 2 & 0.5 \\
\hline 1 & 86 & 8.9 & 56 & 11.8 & 30 & 6.1 & 8 & 3.8 & 27 & 7.5 & 51 & 13.0 \\
\hline 2 & 721 & 74.8 & 326 & 68.9 & 395 & 80.5 & 150 & 71.1 & 280 & 77.8 & 291 & 74.0 \\
\hline 3 & 106 & 11.0 & 71 & 15.0 & 35 & 7.1 & 4 & 1.9 & 53 & 14.7 & 49 & 12.5 \\
\hline \multicolumn{13}{|l|}{ Education§ } \\
\hline 1 & 154 & 16.0 & 86 & 18.2 & 68 & 13.8 & 4 & 1.9 & 28 & 7.8 & 122 & 31.0 \\
\hline 2 & 416 & 43.1 & 193 & 40.8 & 223 & 45.4 & 80 & 37.9 & 160 & 44.4 & 176 & 44.8 \\
\hline 3 & 394 & 40.9 & 194 & 41.0 & 200 & 40.7 & 127 & 60.2 & 172 & 47.8 & 95 & 24.2 \\
\hline \multicolumn{13}{|l|}{ BMI } \\
\hline$<25$ & 650 & 67.4 & 264 & $55.8^{d}$ & 386 & $78.6^{d}$ & 192 & $91.0^{\mathrm{e}}$ & 251 & 69.7 & 207 & $52.7^{\mathrm{e}}$ \\
\hline $25-<30$ & 267 & 27.7 & 191 & 40.4 & 76 & 15.5 & 14 & 6.6 & 94 & 26.1 & 159 & 40.4 \\
\hline$\geq 30$ & 47 & 4.9 & 18 & 3.8 & 29 & 5.9 & 5 & 2.4 & 15 & 4.2 & 27 & 6.9 \\
\hline \multicolumn{13}{|l|}{ Tobacco } \\
\hline Yes & 221 & 22.9 & 122 & $25.8^{f}$ & 99 & $20.2^{f}$ & 77 & $36.5^{\mathrm{g}}$ & 90 & 25.0 & 54 & $13.7^{\mathrm{g}}$ \\
\hline No & 743 & 77.1 & 351 & 74.2 & 392 & 79.8 & 134 & 63.5 & 270 & 75.0 & 339 & 86.3 \\
\hline \multicolumn{13}{|l|}{ Wine } \\
\hline$<100 \mathrm{ml}$ & 634 & 65.8 & 242 & 51.2 & 392 & 79.8 & 176 & 83.4 & 234 & 65.0 & 224 & 57.0 \\
\hline $100-300 \mathrm{ml}$ & 244 & 25.3 & 152 & 32.1 & 92 & 18.7 & 31 & 14.7 & 98 & 27.2 & 115 & 29.3 \\
\hline$>300 \mathrm{ml}$ & 86 & 8.9 & 79 & $16.7^{j}$ & 7 & $1.4^{\mathrm{j}}$ & 4 & $1.9^{k}$ & 28 & 7.8 & 54 & $13.7^{\mathrm{k}}$ \\
\hline \multicolumn{13}{|l|}{ Wine/total alcohol } \\
\hline$<0.33$ & 353 & 36.6 & 129 & $27.3^{1}$ & 224 & $45.6^{1}$ & 119 & $56.4^{\mathrm{m}}$ & 119 & 33.1 & 115 & $29.3^{\mathrm{m}}$ \\
\hline $0.33-0.66$ & 146 & 15.2 & 91 & 19.2 & 55 & 11.2 & 38 & 18.0 & 61 & 16.9 & 47 & 11.9 \\
\hline$>0.66$ & 465 & 48.2 & 253 & 53.5 & 212 & 43.2 & 54 & 25.6 & 180 & 50.0 & 231 & 58.8 \\
\hline \multicolumn{13}{|l|}{ Supplement } \\
\hline Yes & 254 & 26.3 & 72 & $15.2^{n}$ & 182 & $37.1^{n}$ & 66 & 31.3 & 94 & 26.1 & 94 & 23.9 \\
\hline No & 710 & 73.7 & 401 & 84.8 & 309 & 62.9 & 145 & 68.7 & 266 & 73.9 & 299 & 76.1 \\
\hline
\end{tabular}

* Area of residency defined by the number of inhabitants in the relevant community.

† Areas defined by economic activity: Greater Montpellier, area around large urban centre; Bassin de Thau, area around harbour and fisheries; Biterrois, wine growing area; Hauts-Cantons, rural, deserted areas.

$\ddagger$ Occupational activity either of the subject or of the spouse: 0 , without occupational activity (students or unemployed); 1 , workers in industry, farms or fisheries; 2, white-collar workers; 3, executives.

$\S$ Educational level: 1, elementary school; 2, high school; 3, university.

Figures showing the same superscript differ significantly: a, c, d, e, f, g, l, m, n, $P<0.0001 ; \mathrm{b}, P<0.015 ; \mathrm{h}, \mathrm{l}, \mathrm{j}, \mathrm{k}, P<0.001$

Table 3 Median intake values of the subjects classified by the scores of the Diet Quality Index

\begin{tabular}{llccccccc}
\hline & & SFA (\% energy) & Cholesterol $(\mathrm{mg})$ & Meat $(\mathrm{g})$ & Olive oil $(\mathrm{ml})$ & Fish $(\mathrm{g})$ & Cereals $(\mathrm{g})$ & Fruit + vegetables $(\mathrm{g})$ \\
\hline Score 1 & $N=2(0.2 \%)$ & 9.4 & 222.9 & 19.6 & 31.9 & 66.9 & 158.9 & 1023.7 \\
Score 2 & $N=7(0.7 \%)$ & 8.7 & 225.7 & 16.8 & 21.4 & 84.2 & 296.4 & 886.0 \\
Score 3 & $N=23(2.4 \%)$ & 8.4 & 220.0 & 38.5 & 16.6 & 49.0 & 185.7 & 801.5 \\
Score 4 & $N=57(5.9 \%)$ & 9.9 & 218.7 & 38.3 & 19.4 & 37.2 & 185.7 & 824.8 \\
Score 5 & $N=76(7.9 \%)$ & 11.3 & 219.0 & 41.1 & 14.7 & 36.7 & 178.6 & 680.8 \\
Score 6 & $N=122(12.7 \%)$ & 11.4 & 224.3 & 49.2 & 11.5 & 31.3 & 178.6 & 641.6 \\
Score 7 & $N=153(15.9 \%)$ & 12.0 & 240.8 & 56.8 & 7.0 & 26.6 & 178.6 & 577.8 \\
Score 8 & $N=174(18.0 \%)$ & 13.4 & 273.2 & 60.5 & 4.6 & 26.9 & 157.1 & 501.5 \\
Score 9 & $N=150(15.6 \%)$ & 14.8 & 332.6 & 73.0 & 3.3 & 25.7 & 157.1 & 490.7 \\
Score 10 & $N=104(10.8 \%)$ & 14.9 & 315.9 & 72.2 & 1.3 & 20.0 & 156.3 & 353.6 \\
Score 11 & $N=66(6.8 \%)$ & 15.6 & 413.9 & 93.9 & 1.0 & 19.7 & 164.3 & 351.5 \\
Score 12 & $N=23(2.4 \%)$ & 15.9 & 431.1 & 129.0 & 0.0 & 18.6 & 150.0 & 349.5 \\
Score 13 & $N=7(0.7 \%)$ & 15.7 & 460.5 & 168.4 & 1.1 & 15.7 & 92.9 & 188.7 \\
\hline
\end{tabular}


Table 4 Distribution of socio-economic and food-related variables in subjects with Good MDQI and Poor MDQI

\begin{tabular}{|c|c|c|c|c|c|c|c|c|c|c|c|c|c|c|c|c|c|c|c|c|c|c|c|c|}
\hline \multirow[b]{3}{*}{ Residency* $^{*}$} & \multicolumn{4}{|c|}{ Total } & \multicolumn{4}{|c|}{ Men } & \multicolumn{4}{|c|}{ Women } & \multicolumn{4}{|c|}{ 20-34 years } & \multicolumn{4}{|c|}{$35-54$ years } & \multicolumn{4}{|c|}{$55-76$ years } \\
\hline & \multicolumn{2}{|c|}{ Good } & \multicolumn{2}{|c|}{ Poor } & \multicolumn{2}{|c|}{ Good } & \multicolumn{2}{|c|}{ Poor } & \multicolumn{2}{|c|}{ Good } & \multicolumn{2}{|c|}{ Poor } & \multicolumn{2}{|c|}{ Good } & \multicolumn{2}{|c|}{ Poor } & \multicolumn{2}{|c|}{ Good } & \multicolumn{2}{|c|}{ Poor } & \multicolumn{2}{|c|}{ Good } & & oor \\
\hline & & & & & & & & & & & & & & & & & & & & & & & & \\
\hline$<2000$ & 17 & 19.0 & 9 & 9.4 & 12 & 26.7 & 3 & 5.6 & 5 & 11.4 & 6 & 14.3 & 2 & 20.0 & 4 & 9.8 & 4 & 16.7 & 4 & 10.8 & 11 & 20.0 & 1 & 5.6 \\
\hline $2000-10,000$ & 24 & 27.0 & 23 & 23.9 & 11 & 24.4 & 16 & 29.6 & 13 & 29.5 & 7 & 16.7 & 2 & 20.0 & 10 & 24.4 & 8 & 33.3 & 7 & 18.9 & 14 & 25.5 & 6 & 33.3 \\
\hline$>10,000-100,000$ & 24 & 27.0 & 28 & 29.2 & 10 & 22.2 & 14 & 25.9 & 14 & 31.8 & 14 & 33.3 & 2 & 20.0 & 13 & 31.7 & 4 & 16.7 & 10 & 27.0 & 18 & 32.7 & 5 & 27.8 \\
\hline$>100,000$ & 24 & 27.0 & 36 & 37.5 & 12 & 26.7 & $\begin{array}{c}21 \\
P\end{array}$ & $\begin{array}{l}38.9 \\
.034\end{array}$ & 12 & 27.3 & 15 & 35.7 & 4 & 40.0 & 14 & 34.1 & 8 & 33.3 & 16 & 43.3 & 12 & 21.8 & 6 & 33.3 \\
\hline Socio-economic area† & & & & & & & & & & & & & & & & & & & & & & & & \\
\hline Greater Montpellier & 30 & 33.7 & 54 & 56.2 & 15 & 33.3 & 31 & 57.4 & 15 & 34.1 & 23 & 54.8 & 5 & 50.0 & 22 & 53.7 & 9 & 37.6 & 24 & 64.9 & 16 & 29.1 & 8 & 44.4 \\
\hline Bassin de Thau & 24 & 27.0 & 16 & 16.7 & 11 & 24.5 & 7 & 12.9 & 13 & 29.5 & 9 & 21.4 & 1 & 10.0 & 6 & 14.6 & 5 & 20.8 & 6 & 16. & 18 & 32.7 & 4 & 22.2 \\
\hline Biterrois & 26 & 29.2 & 18 & 18.8 & 15 & 33.3 & 11 & 20.4 & 11 & 25.0 & 7 & 16.7 & 3 & 30.0 & 10 & 24.4 & 5 & 20.8 & 5 & 13.5 & 18 & 32.7 & 3 & 16.7 \\
\hline Hauts-Cantons & 9 & 10.1 & $\begin{array}{l}8 \\
P\end{array}$ & $\begin{array}{c}8.3 \\
.021\end{array}$ & 4 & 8.9 & 5 & 9.3 & 5 & 11.4 & 3 & 7.1 & 1 & 10.0 & 3 & 7.3 & 5 & 20.8 & 2 & 5.4 & 3 & 5.5 & 3 & 16.7 \\
\hline Occupation¥ & & & & & & & & & & & & & & & & & & & & & & & & \\
\hline 0 & 2 & 2.3 & 8 & 8.3 & 1 & 2.2 & 5 & 9.3 & 1 & 2.3 & 3 & 7.1 & 2 & 20.0 & 8 & 19.5 & 0 & 0 & 0 & 0 & 0 & 0 & 0 & 0 \\
\hline 1 & 13 & 14.4 & 5 & 5.2 & 10 & 22.2 & 5 & 9.3 & 3 & 6.8 & 0 & 0 & 0 & 0 & 1 & 2.4 & 3 & 12.5 & 1 & 2.7 & 10 & 18.2 & 3 & 16.7 \\
\hline 2 & 64 & 71.9 & 74 & 77.1 & 29 & 64.5 & 38 & 70.3 & 35 & 79.5 & 36 & 85.8 & 8 & 80.0 & 32 & 78.1 & 17 & 70.8 & 29 & 78.4 & 39 & 70.9 & 13 & 72.2 \\
\hline 3 & 10 & 11.2 & 9 & 9.4 & 5 & 11.5 & 6 & 11.1 & 5 & 11.4 & 3 & 7.1 & 0 & 0 & 0 & 0 & 4 & 16.7 & 7 & 18.9 & 6 & 10.9 & 2 & 11.1 \\
\hline duc & & & & & & & & & & & & & & & & & & & & & & & & \\
\hline 1 & 23 & 25.8 & 8 & 8.4 & 13 & 28.9 & 7 & 13.0 & 10 & 22.8 & 1 & 2.4 & 0 & 0 & 1 & 2.5 & 2 & 8.3 & 3 & 8.1 & 21 & 38.2 & 4 & 22.2 \\
\hline 2 & 34 & 38.2 & 44 & 45.8 & 17 & 37.8 & 19 & 35.2 & 17 & 38.6 & 25 & 59.5 & 2 & 20.0 & 21 & 51.2 & 10 & 41.7 & 13 & 35.1 & 22 & 40 & 10 & 55.6 \\
\hline 3 & 32 & 36.0 & 44 & 45.8 & 15 & 33.3 & 28 & 51.8 & 17 & 38.6 & 16 & 38.1 & 8 & 80.0 & 19 & 46.3 & 12 & 50.0 & 21 & 56.8 & 12 & 21.8 & 4 & 22.2 \\
\hline BMI & & & & & & & & & & & & & & & & & & & & & & & & \\
\hline$<25$ & 57 & 64.0 & 68 & 70.8 & 23 & 51.1 & 31 & 57.4 & 34 & 77.3 & 37 & 88.1 & 9 & 90.0 & 39 & 95.1 & 16 & 66.7 & 24 & 64.9 & 32 & 58.2 & 5 & 27.8 \\
\hline $25-<30$ & 30 & 33.7 & 26 & 27.1 & 20 & 44.4 & 23 & 42.6 & 10 & 22.7 & 3 & 7.1 & 1 & 10.0 & 2 & 4.9 & 8 & 33.3 & 13 & 35.1 & 21 & 38.2 & 11 & 61.1 \\
\hline$\geq 30$ & 2 & 2.2 & 2 & 2.1 & 2 & 4.4 & 0 & & 0 & & 2 & 4.8 & 0 & & 0 & & 0 & & 0 & & 2 & 3.6 & 2 & 11.1 \\
\hline Tobacc & & & & & & & & & & & & & & & & & & & & & & & & \\
\hline Yes & 9 & 10.1 & 33 & 34.4 & 4 & 9.1 & 24 & 44.4 & 4 & 9.1 & 9 & 21.4 & 3 & 30.0 & 16 & 39.0 & 2 & 8.3 & 13 & 35.1 & 4 & 7.3 & 4 & 22.2 \\
\hline No & 80 & 89.9 & 63 & 65.6 & 40 & 90.9 & 30 & 55.6 & 40 & 90.9 & 33 & 78.6 & 7 & 70.0 & 25 & 61.0 & 22 & 91.7 & 24 & 64.9 & & 2.7 & 14 & 77.8 \\
\hline & & & & & & & & 001 & & & & & & & & & & & & & & & & \\
\hline Wine & & & & & & & & & & & & & & & & & & & & & & & & \\
\hline$<100 \mathrm{ml}$ & 57 & 64.0 & 67 & 69.8 & 35 & 79.5 & 32 & 59.3 & 35 & 79.5 & 35 & 83.3 & 6 & 60.0 & 36 & 87.8 & 18 & 75.0 & 22 & 59.5 & 33 & 60.0 & 9 & 50.0 \\
\hline $100-300 \mathrm{ml}$ & 24 & 27.0 & 18 & 18.7 & 9 & 20.5 & 12 & 22.2 & 9 & 20.5 & 6 & 14.3 & 3 & 30.0 & 5 & 12.2 & 4 & 16.7 & 10 & 27.0 & 17 & 30.9 & 3 & 16.7 \\
\hline$>300 \mathrm{ml}$ & 8 & 9.0 & 11 & 11.5 & 0 & & 10 & 18.5 & 0 & & 1 & 2.4 & 1 & 10.0 & 0 & & 2 & 8.3 & 5 & 13.5 & 5 & 9.1 & 6 & 33.3 \\
\hline Wine/total & & & & & & & & & & & & & & & & & & & & & & & & \\
\hline$<0.33$ & 33 & 37.1 & 39 & 40.6 & 22 & 50.0 & 19 & 35.2 & 22 & 50.0 & 20 & 47.6 & 39 & 40.6 & 29 & 70.7 & 11 & 45.8 & 8 & 21.6 & 18 & 32.7 & 2 & 11.1 \\
\hline $0.33-0.66$ & 16 & 18.0 & 20 & 20.8 & 4 & 9.1 & 13 & 24.1 & 4 & 9.1 & 7 & 16.7 & 20 & 20.8 & 5 & 12.2 & 5 & 20.8 & 11 & 29.7 & 10 & 18.2 & 4 & 22.2 \\
\hline$>0.66$ & 40 & 44.9 & 37 & 38.5 & 18 & 40.9 & 22 & 40.7 & 18 & 40.9 & 15 & 35.7 & 37 & 38.5 & 7 & 17.1 & 8 & 33.3 & 18 & 48.6 & 27 & 49.1 & 12 & 66.7 \\
\hline
\end{tabular}

* Area of residency defined by the number of inhabitants in the relevant community.

† Areas defined by economic activity: Greater Montpellier, area around large urban centre; Bassin de Thau, area around harbour and fisheries; Biterrois, wine growing area; Hauts-Cantons, rural, deserted areas. ¥ Occupational activity either of the subject or of the spouse: 0 , without occupational activity (students or unemployed); 1 , workers in industry, farms or fisheries; 2, white-collar workers; 3 , executives.

$\S$ Educational level: 1, elementary school; 2, high school; 3, university.

Values in italic are percentages. 
distribution of subjects and women with a good diet was significantly different from those with a bad diet, the subjects with a good diet were more likely to have a lower educational level. Among the distribution of the individual variables the only significant difference between subjects having a good diet and subjects having a poor one pertained to tobacco use. The distribution difference between good diet and bad diet groups was significant for all subjects, men and medium-aged subjects. For BMI, alcohol and wine intake and wine/total alcohol ratio, there were no significant differences in the distribution of the three classes of these variables. However, there was a significant difference between the distribution of good and bad diet subjects when these variables were stratified in two classes only, because of the small number of subjects in some categories. For 55-76 year old subjects, the comparison of the distribution of $<25$ and $\geq 25$ BMI classes was significantly different $(P=0.025)$ between the good and poor diet groups, more subjects with a high BMI being in the poor diet group. When wine consumption was stratified in two classes ( $\leq 300 \mathrm{ml}$ and $>300 \mathrm{ml}$ ), the test showed that the distribution of the 55-76 year olds was significantly different $(P=0.034)$, with more subjects drinking less wine in the good diet group. With regard to the contribution of wine to the total alcohol intake, the opposite findings were suggested by the comparison of the distribution of two classes of the variable between the poor and the good diet of the 20-34 year olds and the other two age classes. There was an indication $(P=0.08)$ that the distribution of the extreme classes of the variable $(<0.33$ and $>0.66)$ was different in the 20-34 year olds with more young subjects having the highest contribution of wine to alcohol intake in the good diet group. The reverse was observed for the 35-54 and 55-76 year olds ( $P=0.07$ and 0.08 , respectively), the proportion of subjects in the poor diet group being highest in the highest tertile of the variable. This finding reached significance $(P=0.046)$ for the medium aged class when the $<0.33$ and $\geq 0.33$ wine alcohol/total alcohol ratio classes were compared.

The results of the correspondence analysis are shown in Fig. 1 for men and in Fig. 2 for women. The values represented on Dimension 1 provide most of the information on MDQI, with $78.7 \%$ of the information for men and $77.5 \%$ for women. The information on Dimension 2 is less important (13.0\% of the information for men and $16.7 \%$ for women).

For men, age contributes the most information on MDQI (0.16): 55-76 year olds with a good MDQI are at the positive extremity and 20-34 year olds with a poor MDQI towards the negative extremity of Dimension 1. Also represented on Dimension 1 and associated with a good MDQI are a low level of education, occupation as a manual worker and residence in a rural area, although the contribution of the last variable is very modest. At the other extremity, smoking is associated with a poor MDQI

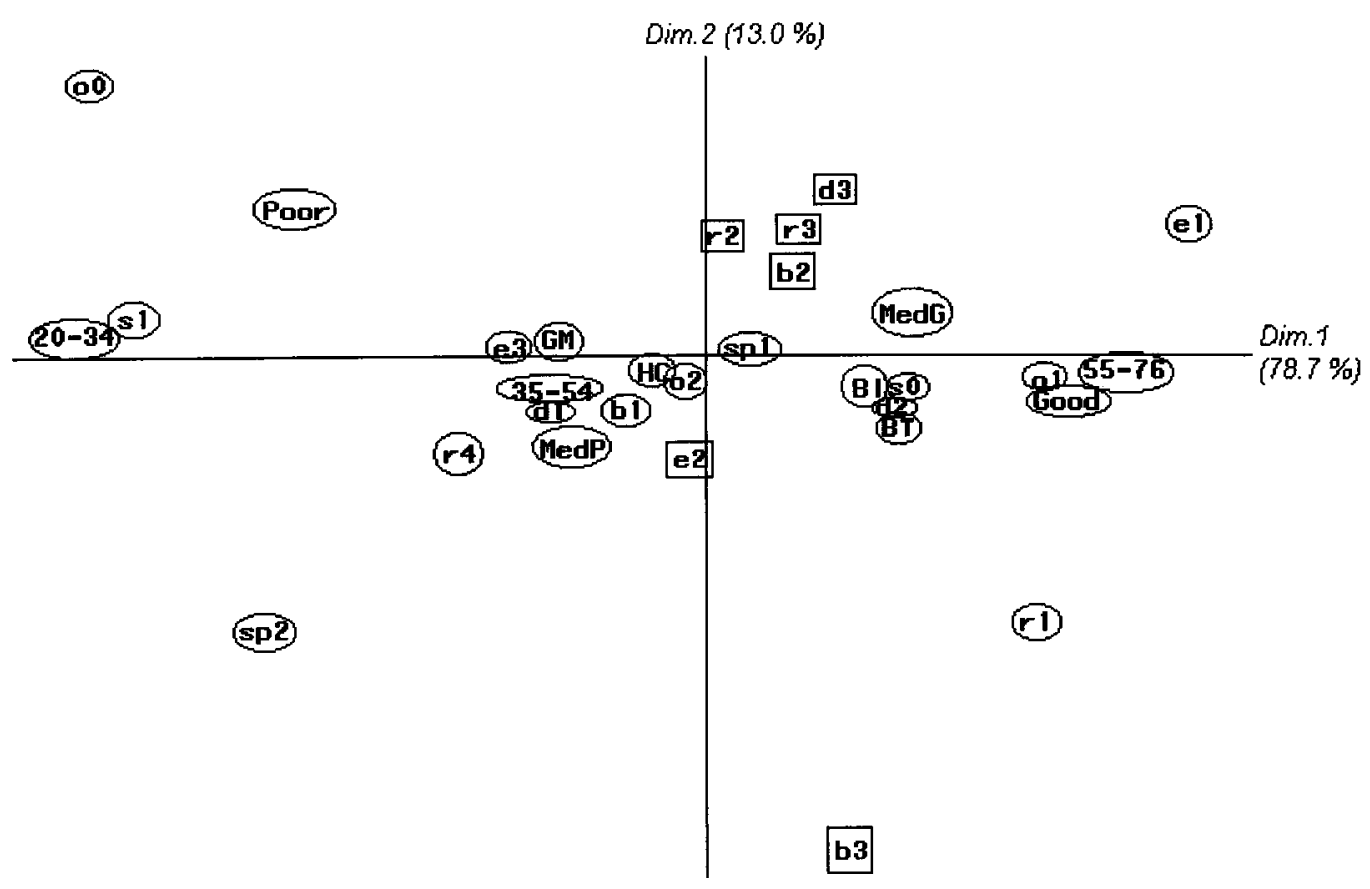

Fig. 1 Correspondence analysis in men. A circle surrounds the variables contributing mainly to Dimension 1 and those contributing mainly to Dimension 2 are surrounded by a square. MedP, medium poor; MedG, medium good. Age classes: 20-34, 35-54, and 55-76 years. BMI:

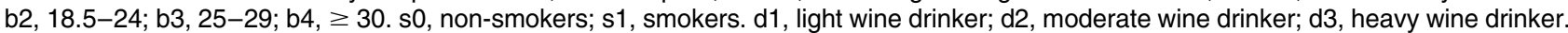
sp2, supplement use. e1, elementary school; e2, high school; e3, university. o0, without occupational activity (students or unemployed); o1, workers in industry, farms or fisheries. $r 1,<2000$ inhabitants; r2, 2000-10,000 inhabitants; $r 4,>100,000$ inhabitants. BI, Bitterrois; GM, Greater Montpellier 


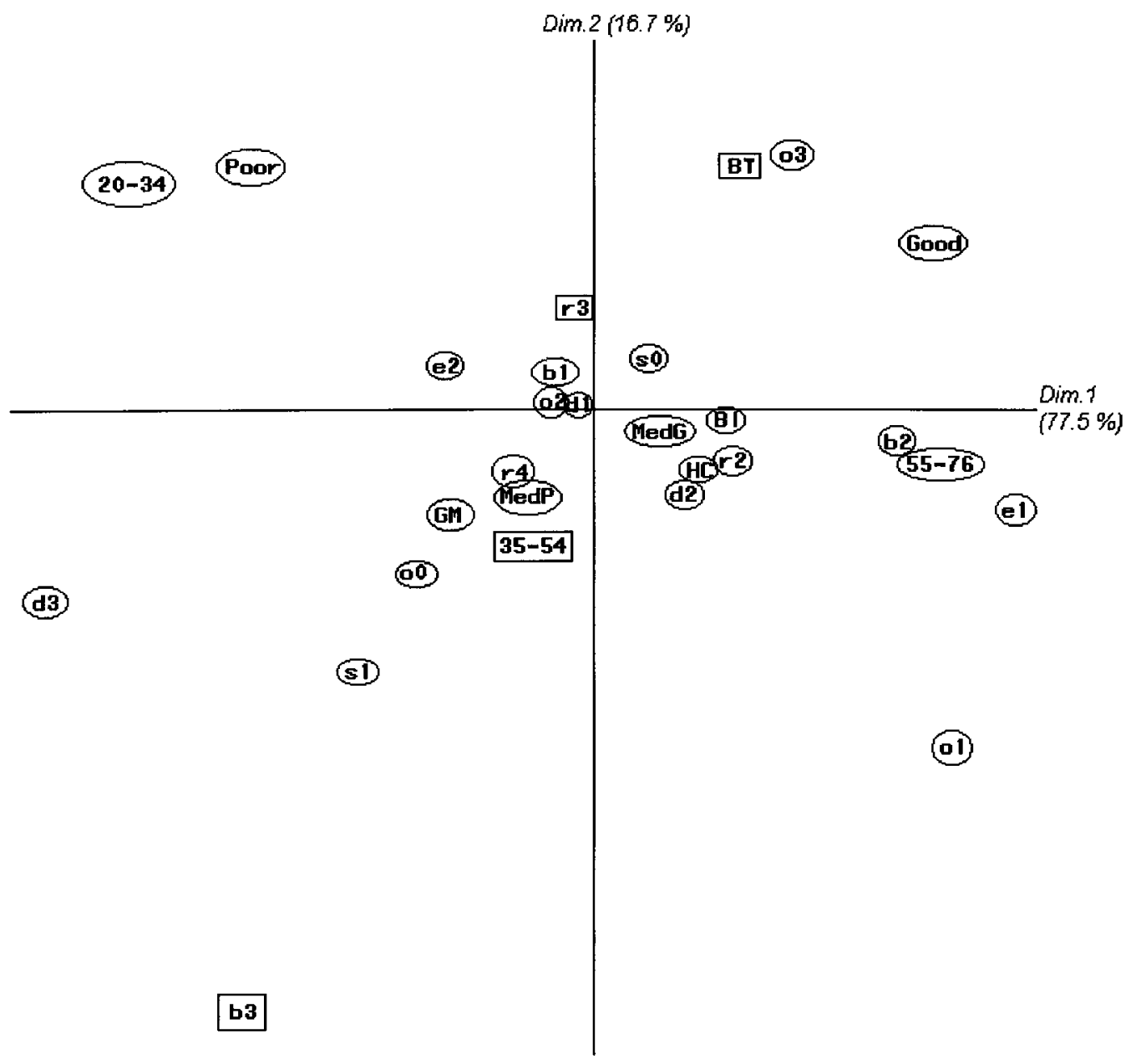

Fig. 2 Correspondence analysis in women. A circle surrounds the variables contributing mainly to Dimension 1 and those contributing mainly to Dimension 2 are surrounded by a square. MedP, medium poor; MedG, medium good. Age classes: 20-34, 35-54 and 55-76 years. BMI: b1, <18.5; b2, 18.5-24; b3, 25-29; b4, 30. s1, smokers. d2, moderate wine drinker; d3, heavy wine drinker. e1, elementary school; e2, high school; o1, worker or spouse of worker in industry, farms or fisheries; o3, executive or executive's spouse. r2, 2000-10,000 inhabitants; $\mathrm{r} 3,>10,000$ to $\leq 100,000$ inhabitants. BI, Bitterrois; BT, Bassin de Thau; GM, Greater Montpellier

(0.17), whereas being a student and taking supplements are less well represented on this dimension. Moderate drinking habits (d2), situated halfway between the origin and the positive extremity of Dimension 1, are associated with non-smoking and living in small towns surrounded by rural areas (r1) (Bitterrois and Bassin de Thau). These variables appear to contribute to the information on subjects with a Medium-to-Good diet, whereas the Medium-to-Poor diet appears on Dimension 1 halfway along the negative side, close to the $35-54$ year old age class and light wine drinkers (d1), residence in large towns or the Greater Montpellier area and a higher level of education. Being rather lean (b1), living in the HautsCantons area, having a middle-class occupation (02) and not taking supplements (sp1) are in the middle, between Poor and Good diet. The variables d3 (heavy drinker), r2 and r3 (small town), b2 and b3 (overweight and obese) and e2 (medium level of education) contribute mainly to Dimension 2. They appear to separate Medium-to-Poor diet (e2 and b3) from Poor diet (b2, r2, r3 and d3), but the contribution of Dimension 2 is relatively minor.

For women, membership of the 55-76 year old age class, a low level of education and occupation as a manual worker (or wife of a manual worker) contribute most to the information on Good MDQI, as with men. However, living in a rural area is absent, and being overweight appears close to the age variable. Variable o3 (executive or wife of an executive) appears halfway between Good and Medium-to-Good MDQI. Close to the latter on Dimension 1 are subjects living in small towns and rural areas (r2, Bitterrois, Hauts-Cantons), nonsmokers and moderate drinkers. Smoking appears between Poor and Medium-to-Poor MDQI. Obesity (b3), membership of the 35-54 year old age class, residence in a medium-sized town and/or in the Bassin de Thau contributes mainly to Dimension 2 to separate Mediumto-Poor MDQI from Poor MDQI and Medium-to-Good MDQI from Good MDQI. 


\section{Discussion}

To analyse the dietary habits of the southern French population under study, we adapted a DQI ${ }^{13}$ to the food habits of our region and to the Mediterranean model, which appears beneficial in countering most chronic degenerative diseases, as supported by many scientific reports $^{28-39,41-44}$. We decided on a score close to our objectives $^{13}$ in preference to others focused on variety and diversity ${ }^{45}$. Two composite diet scores have been used for evaluating the relationship between Mediterranean diet and the southern European population ${ }^{46,47}$. However, because the objectives of these studies were different (estimation of diet-related risk rather than classification of subjects' food habits) the design of the scores was different, with only a single cut-off below and above the median food consumption of the sample, and cannot be compared with ours. Also the estimation of fat intake was somewhat more precise in our score, which differentiated between a 'saturated fat' category containing dairy products and one for 'olive oil', the intake of which was measured directly.

The steady progression of the various items across the scores gave us a coherent set of results. Cereal intake was the most resistant item to progressive scoring. First, because cereals are difficult to classify as 'nutritionally good' or 'poor' food, they can be described as a risk factor $^{48,49}$ if highly refined and eaten in large quantities (especially as sandwiches) by inactive people. In contrast, whole-grain cereals have been reported as protective $\mathrm{e}^{50,51}$ but could not be used as such in our sample as not enough subjects ate them. Second, cereals tend to replace meat as a staple food in poor diets (scores 11-13), suggesting that an economic factor sometimes plays a part in the high scores.

With this limitation, the selected variables appear to provide an overall assessment of food habits in this region of southern France and are supported by the validation using biomarkers (plasma $\beta$-carotene and vitamin $\mathrm{E}$, erythrocyte fatty acids, and serum cholesterol ${ }^{16}$ ) in a subsample of the study. We can therefore have confidence in its validity for the measurement of nutritional status.

The representative nature of the sample needs to be established before our results can be extended to the Hérault population as a whole and conclusions drawn with regard to the prevention of disease by nutritional means. The distribution of two variables found associated with the profile Good and/or Poor MDQI, age and residence, was comparable between responders and nonresponders.

We also compared the consumption of 55-76 year olds in the Hérault sample with the 1993 assessment of the Seneca study. The results for macronutrient consumption in the Hérault were close to those obtained in the two French towns (Haguenau and Roman, northern and eastern France, respectively) covered by the study ${ }^{52}$.
However, the percentage of energy provided by saturated fatty acids and vitamin $C$ and $\beta$-carotene intake were closer to Spanish figures than to the figures for the two French towns in the Seneca study ${ }^{53}$, as was to be expected from the geographical context.

The correspondence analysis describes the profile of the subjects with a good or a poor diet. We chose this method because dietary behaviour is a complex phenomenon with multiple markers and/or factors that need to be identified, although their contribution is moderate or weak if one wishes to set up nutritional prevention strategies.

The strongest finding of our study is the influence of age on the dietary habits of both men and women, with older subjects having a better MDQI than younger people. One explanation may be that older people are more careful than young people about their health. Alternatively, it might be that older people continue to eat traditional Mediterranean food. This is supported by the association of the Good and Medium-to-Good diets with residence in rural areas and sub-regions. The recruitment method used in our study ensured that residence was independent of age (Table 2). Other factors (such as education, occupation and, to a lesser extent, obesity) contributing to information on the MDQI could be confounded by age, as shown in Table 2. But it has similarly been reported in another French study ${ }^{54}$ that traditional food habits are maintained among workingclass subjects. The association has also been described in a Spanish study ${ }^{55}$ : in an approach limited to fruit and vegetable consumption as protective factors against chronic degenerative diseases, Agudo et al. ${ }^{55}$ studied the association of single lifestyle factors with fruit and vegetable consumption in a 29-69 year old Spanish population. If fruit and vegetable consumption is considered to be a marker for a Mediterranean diet, Agudo et al.'s results ${ }^{55}$ can be compared with ours. In their results, being a heavy manual worker, a non-smoker and having a high intake of monounsaturated fatty acids (mainly olive oil) was positively associated with fruit and vegetable intake, in line with our findings. However, in contrast to our study, alcohol intake was inversely associated with high fruit and vegetable intake. They also showed, in univariate analysis, that high fruit and vegetable consumption was associated both with manual workers and with university-educated subjects. The correspondence analysis in the present study showed that women executives and wives of executives appeared close to wives of manual workers in the Good MDQI profile.

In conclusion, our study confirms the association of smoking with poor dietary habits ${ }^{56}$. Moderate wine drinking is not related to poor dietary habits. This reflects the strong association between the Mediterranean diet and wine drinking. However, more 55-76 year old subjects with a high consumption of wine are found in 
the poor diet group. The correspondence analysis suggested that men and women differ with regard to wine drinking, since heavy drinking was associated with a Poor MDQI in women and light drinking with a Mediumto-Poor MDQI in men. Factors such as obesity and drinking associated with poor diet in young women suggest a different behaviour from that of young men, for whom the associated variables of being a student and using supplements may be more circumstantial.

In as far as our sample is representative of the Hérault population, young subjects appear to be a group at risk and the primary target for a nutritional prevention policy. However, the way to implement such a policy may be different for young men and young women. The study also indicates that traditional food habits are disappearing from the most highly urbanized areas and focuses attention on the importance of socio-economic factors, such as income, demographic characteristics, employment, women's activities and the number of supermarkets and fast-food outlets, in the dietary habits of the different populations. Pluridisciplinary teams including nutritionists, public health workers, psychologists, sociologists and economists are therefore required to implement a nutritional public health policy.

\section{Acknowledgements}

We thank Marie-Hélène Avallone for her field work, Robert Goulevitch for his editing and Garth Evans for his assistance with the English. This work has been financially supported by the Prevôt Foundation, the Hérault and Ardèche committees of the Ligue contre le Cancer and the Languedoc-Roussillon Regional Council.

\section{References}

1 Rapola JM, Virtamo J, Ripatti S, Huttunen JK, Albanes D, Taylor PR, Heinonen OP. Randomised trial of alphatocopherol and beta-carotene supplements on incidence of major coronary events in men with previous myocardial infarction. Lancet 1997; 349: 1715-20.

2 Omenn GS, Goodman GE, Thornquist MD, Balmes J, Cullen MR, Glass A. Effects of a combination of beta carotene and vitamin A on lung cancer and cardiovascular disease. $N$. Engl. J. Med. 1996; 334: 1150-5.

3 GISSI-Prevenzione Investigators. Dietary supplementation with n-3 polyunsaturated fatty acids and vitamin $\mathrm{E}$ after myocardial infarction: results of the GISSI-Prevenzione trial. Lancet 1999; 354: 447-54.

4 The Heart Outcomes Prevention Evaluation Study Investigators. Vitamin E supplementation and cardiovascular events in high-risk patients. N. Engl. J. Med. 2000; 342: 154-60.

5 ATBC, The Alpha-Tocopherol Beta-Carotene Cancer Prevention Study Group. The effect of vitamin E and beta carotene on the incidence of lung cancer and other cancers in male smokers. N. Engl. J. Med. 1994; 330: 1029-35.

6 Omenn GS, Goodman GE, Thornquist MD, Balmes J, Cullen MR, Glass A, et al. Risk factors for lung cancer and for intervention effects in CARET, the beta carotene and Retinol Efficacy Trial. J. Natl. Cancer Inst. 1996; 88: 1550-9.

7 Greenberg ER, Baron Ja, Tosteson TD, Freeman DH, Beck
GJ, Bond JH, et al. (Polyp Prevention Study Group). A clinical trial of antioxidant vitamins to prevent colorectal adenoma. N. Engl. J. Med. 1994; 331(3): 141-7.

8 MacLennan R, MacRae F, Bain C, Battistutta D, Chapuis P, Gratten $\mathrm{H}$, et al. Randomized trial of intake of fat, fiber, and beta carotene to prevent colorectal adenomas. J. Natl. Cancer Inst. 1995; 87: 1760-6.

9 Blot WJ, Li HY, Taylor PR, Guo W, Dawsey S, Wang GQ, et al. Nutrition intervention trials in Linxian, China: supplementation with specific vitamin/mineral combinations, cancer incidence, and disease-specific mortality in the general population. J. Natl. Cancer Inst. 1993; 85(18): 1483-92.

10 Yong L-C, Brown CC, Schatzkin A, Dresser CM, Slesinski MJ, Cox CS, et al. Intake of vitamins E, C, and A and risk of lung cancer. The NHANES I epidemiologic follow up study. Am.J. Epidemiol. 1997; 146: 231-43.

11 Dowler E, Calvert C. Nutrition and Diet in Lone-parent Families in London. London: Family Policy Studies Centre, ed. Joseph Rowntree Foundation, 1995.

12 Davenport M, Roderick P, Elliott L, Victor C, Geissler C. Monitoring dietary change in populations and the need for specific food targets; lessons from the North West Thames regional health survey. J. Hum. Nutr. Diet. 1995; 8: 119-28.

13 Patterson RE, Haines PS, Popkin BM. Diet quality index: capturing a multidimensional behavior. J. Am. Diet. Assoc. 1994; 94: 57-64.

14 Haines PS, Siega-Riz AM, Popkin BM. The diet quality index revised: a measurement instrument for populations. J. Am. Diet. Assoc. 1999; 99: 697-704.

15 National Research Council. Committee on Diet and Health, Food and Nutrition Board, Commission on Life Sciences. Diet and Health: Implications for Reducing Chronic Disease Risk. Washington, DC: National Academy of Sciences, 1989.

16 Gerber M, Scali J, Michaud A, Durand M, Astre C, Dallongeville $\mathrm{J}$, et al. Profiles of a healthy diet and its relationship with biomarkers in a population sample from Mediterranean Southern France. J. Am. Diet. Assoc. 2000; 100: 1164-71.

17 Gerber M, Siari S, Michaud A, Scali J. Alimentation méditerranéenne et santé. MEDHEA: résultats de l'Hérault. Actual. Diét. 1999; 35: 1391-7.

18 Padilla M. Consommer méditerranéen une action préventive au cancer. Rapport à la CE (DGV, contrat No. SOC 97200420 05F02).

19 Ainsworth BE, Haskell WL, Leon AS, Jacobs DR, Montoye HJ, Sallis JF, et al. Compendium of physical activities: classification of energy costs of human physical activities. Med. Sci. Sports Exercise 1993; 25: 71-80.

20 Bonifacj C, Gerber M, Scali J, Daurès JP. Comparison of dietary assessment methods in a Southern French population. Use of weighed records, estimated-diet records and a food-frequency questionnaire. Eur. J. Clin. Nutr. 1997; 51: 217-31.

21 Gerber M, Cavallo F, Marubini E, Richardson S, Barbieri A, Capitelli E, et al. Liposoluble vitamins and lipid parametres in breast cancer. A joint study in Northern Italy and Southern France. Int. J. Cancer 1988; 42: 489-94.

22 Richardson S, Gerber M, Cénée S. The role of fat, animal protein and vitamin consumption in breast cancer. A casecontrol study in Southern France. Int. J. Cancer 1991; 48: 1-9.

23 Scali J, Segala C, Astre C, Gerber M. Serum cholesterol, plasma and dietary beta carotene in lung cancer. Eur. J. Cancer Prev. 1993; 4: 169-74.

24 Volatier J-L, Chambolle M. Les disparités régionales de la consommation alimentaire des ménages français. Ed. Credoc. Paris: Cnerna, 1996.

25 Paul AA, Southgate DAT. In: McCance, Widdowson, eds. The Composition of Food, th edition. London: HMSO, 1978.

26 Feinberg M, Favier JC, Ireland-Ripert J. Répertoire Général des Aliments, ed. Tec Doc. Paris: Lavoisier, 1991. 
27 Krauss RM, Deckelbaum RJ, Ernst N, Fisher E, Howard BV, Knopp RH, et al. Dietary guidelines for healthy American adults. A statement for health professionals from the Nutrition Committee, American Heart Association. Circulation 1996; 94: 1795-800.

28 Kushi LH, Lenart EB, Willett WC. Health implications of mediterranean diets in light of contemporary knowledge. 1. Plant foods and dairy products. 2 . Meats, wine, fats, and oils. Am. J. Clin. Nutr. 1995; 61: S1407-27.

29 Corpet DE, Gerber M. Alimentation méditerranéenne et Santé. I-Caractéristiques. Maladies cardio-vasculaires et autres affections. Méd. Nutr. 1997; 4: 129-42.

30 Gerber M, Corpet D. Alimentation méditerranéenne et Santé. II-Cancers. Méd. Nutr. 1997; 4: 143-54.

31 Sacks FM, Donner A, Castelli WP, Gronemeyer J, Pletka P, Margolius HS, et al. Effects of ingestion of meat on plasma cholesterol of vegetarians. Jama 1981; 246: 640-4.

32 Kromhout D, Bosschieter EB, Coulander CR. The inverse relationship between fish consumption and 20-year mortality from coronary heart disease. N. Engl. J. Med. 1985; 312: 1205-9.

33 Daviglus ML, Stamler J, Orencia AJ, Dyer AR, Liu K, Greenland $\mathrm{P}$, et al. Fish consumption and the 30-year risk of fatal myocardial infarction. N. Engl. J. Med. 1997; 336: 1046-3.

34 Potter JD, Slattery ML, Bostick RM, Gapstur SM. Colon cancer: a review of the epidemiology. Epidemiol. Rev. 1993; 15: 499-545.

35 Goldbohm RA, Van Den Brandt PA, Van’T Veer P, Brants HA, Doran E, Sturmans F, et al. A prospective cohort study on the relation between meat consumption and the risk of colon cancer. Cancer Res. 1994; 54: 718-23.

36 Hsing AW, McLaughlin JK, Chow W-HO, Schuman LM, Co Chien HT, Gridley G, et al. Risk factors for colorectal cancer in a prospective study among US white men. Int. J. Cancer 1998; 77: 549-53.

37 Kaiser L, Boyd NF, Kriukov V, Tritchler D. Fish consumption and cancer risk: an ecological study. Nutr. Cancer 1989; 12: 61-8.

38 Giovannucci E, Goldin B. The role of fat, fatty acids, and total energy intake in the etiology of human colon cancer. Am.J. Clin. Nutr. 1997; 66S: 1564S-71S.

39 Favero A, Parpinel M, Franceschi S. Diet and risk of breast cancer: major findings from an Italian case-control study. Biomed. Pharmarcother. 1998; 52: 109-15.

40 WHO. Report of a WHO consultation on obesity: preventing and managing the global epidemic. Geneva: WHO, 1998.

$41 \mathrm{Yu}$ S, Serr J, Etherton TD, Kris-Etherton PM. Plasmacholesterol-predictive equations demonstrate that stearic acid is neutral and monounsaturated fatty acids are hypocholesterolemic. Am. J. Clin. Nutr. 1995; 61: 1129-39.
42 Martin-Moreno JM, Willet WC, Gorgojo L, Banegas Jr, Rodriguez-Artalejo F, Fernandez-Rodriguez JC, et al. Dietary fat, olive oil intake and breast cancer risk. Int.J. Cancer 1994; 58: 774-80.

43 Trichopoulou A, Kouris-Blazos A, Wahlqvist M, Gnardellis C, Lagiou P, Polychronopoulos E, et al. Diet and overall survival in elderly people. Br. Med. J. 1995; 311: 1457-60.

44 Fortes C, Forastiere F, Anatra F, Schmid G. Re: consumption of olive oil and specific food groups in relation to breast cancer risk in Greece. J. Natl. Cancer Inst. 1995; 87: 1020-1.

45 Drenowski A, Henderson SA, Driscoll A, Rolls BJ. The Dietary Variety Score: assessing diet quality in healthy young and older adults. J. Am. Diet. Assoc. 1997; 97: 266-71.

46 Trichopoulou A, Kouris-Blazos A, Wahlqvist ML, Gnardellis C, Lagiou P, Polychronopoulos E, et al. Diet and overall survival in elderly people. BMJ 1995; 311: 1457-60.

47 Lasheras C, Fernandez S, Patterson AM. Mediterranean diet and age with respect to overall survival in institutionalized, nonsmoking elderly people. Am. J. Clin. Nutr. 2000; 71: 987-92.

48 Franceschi S, Favero A, Decarli A, La Vecchia C, Ferraroni M, Russo A, et al. Intake of macronutrients and risk of breast cancer. Lancet 1996; 347: 1351-6.

49 Franceschi S, Favero A, Parpinel M, Giacosa A, La Vecchia C. Italian study on colorectal cancer with emphasis on influence of cereals. Eur. J. Cancer Prev. 1998; 7S: S19-23.

50 La Vecchia C, Chatenoud L. Fibres, whole-grain foods and breast and other cancers. Eur. J. Cancer Prev. 1998; 7S: S25-8.

51 Levi F, Pasche C, La Vecchia C, Lucchini F, Franceschi S. Food groups and colorectal cancer risk. Br. J. Cancer 1999; 79: $1283-7$

52 Moreiras O, van Staveren WA, Amorim Cruz JA, Carbajal A, de Henauw S, Grunenberger Roszkowski W (SENECA Investigators). Longitudinal changes in the intake of energy and macronutrients of elderly Europeans. Eur. J. Clin. Nutr. 1996; 50: S67-76.

53 Amorim Cruz JA, Moreiras O, Brzozowska A (SENECA Investigators). Longitudinal changes in the intake of vitamins and minerals of elderly Europeans. Eur. J. Clin. Nutr. 1996; 50: $577-85$.

54 Poulain JP. Mutation des pratiques et nouvelles formes d'équilibre alimentaire. Actes des Ivemes rencontres du Réseau Agronomique Méditerranéen. Avignon, Agroparc, 1998; 77-93.

55 Agudo A, Pera G. EPIC Group of Spain. Vegetable and fruit consumption associated with anthropometric, dietary and lifestyle factors in Spain. Public Health Nutr. 1999; 2: $263-$ 71.

56 Dallongeville J, Marecaux N, Fruchart JC, Amouyel P. Cigarette smoking is associated with unhealthy patterns of nutrient intake: a meta-analysis. J. Nutr. 1998; 128(9): 1450-7. 